\title{
Effect of Spheroidization Annealing on Pearlite Banding
}

\section{Sergey Guk ${ }^{1, a^{*}}$, Eva Augenstein ${ }^{2, b}$, Maksim Zapara ${ }^{2, c}$, Rudolf Kawalla ${ }^{1, d}$ and Ulrich Prahl ${ }^{1, e}$}

\author{
${ }^{1}$ Institut für Metallformung, Bernhard-von-Cotta-Str. 4, Technische Universität Bergakademie \\ Freiberg, 09599, Germany \\ ${ }^{2}$ Fraunhofer Institute for Mechanics of Materials IWM, Wöhlerstr. 11, 79108, Germany \\ aSergey.Guk@imf.tu-freiberg.de, bEva.Augenstein@iwm.fraunhofer.de, \\ cMaksim.Zapara@iwm.fraunhofer.de, dRudolf.Kawalla@imf.tu-freiberg.de, \\ eUlrich.Prahl@imf.tu-freiberg.de \\ *the corresponding author
}

\begin{abstract}
Keywords: pearlite banding, segregation, spheroidization annealing, hypoeutectoid steel
\end{abstract}
\begin{abstract}
The present paper deals with the influence of the duration of isothermal spheroidization annealing on the evolution of pearlite bands in various initial states. In this study, two initial conditions of the steel $16 \mathrm{MnCrS5}$ are considered: a) industrially hot-rolled pearlite structures in their ferritic matrix and b) a specifically adjusted microstructure in the lab condition. Based on the experimental investigations and quantitative microstructural analyses, an empirical model for the prediction of pearlite banding within a broad range of annealing durations could be derived. Both, experiment and model, agree that pronounced pearlite bands in the initial state almost disappear after $25 \mathrm{~h}$ of spheroidization annealing. On the other hand, a marginal degree of pearlite banding in the initial state increases slightly during annealing. This fact could be explained by inhomogeneous cementite formation inside and outside the primary segregation regions of manganese.
\end{abstract}

\section{Introduction}

As-rolled steels often exhibit an inhomogeneous microstructure in terms of pearlite banding owing to primary segregations. The represent chemical inhomogeneities at the micro- and macroscale which may arise during directional solidification due to the accumulation and depletion of alloying elements in the unsolidified region. Segregations arrange during crystallization and severely deform by subsequent hot forging to a semi-finished part. They affect the formation of the microstructure through both, the local changes of transformation temperatures and the shift of the excess carbon by cooling from the transformation front into the untransformed austenitic regions. The result is pearlite banding [1].

Various disadvantages of pronounced pearlite banding for the further processing of semi-finished parts are reported in literature: In general, it is believed that the deformation of the anisotropic microstructure can lead to premature material failure due to localized stress peaks $[2,3]$. In addition, there is a risk of subsequent failure by hardening, or of distortion in the case of non-heat treated parts [4]. A reduced fatigue strength and toughness of the finished product are further negative consequences of pronounced pearlite banding [5].

State of the art for producing high strength cold formed parts includes heat treatment (tempering or annealing) of carbon steels and low-alloyed carbon steels. In order to enable a sufficient tool life the wire materials is subjected to spheroidization annealing (annealing to spherical cementite) before cold forming. It is known that low cooling rates within the transformation temperature range provoke pearlite/carbide banding or increase its severity [6]. The literature analysis reveals some evidence in favor of this hypothesis, although there are no comprehensible findings on the origin or development of pearlite banding during spheroidization annealing.

For this reason, the present study aims to quantify the effect of spheroidization annealing on the various degrees of pearlite banding in as-rolled steel. 


\section{Material and Methods}

The investigated material was a grade $16 \mathrm{MnCrS5}$ steel delivered as a hot-rolled wire rod with diameter $11.0 \mathrm{~mm}$. Its chemical composition is shown in Table 1.

Table 1: Chemical composition of the investigated steel in wt.\%

\begin{tabular}{l|l|l|l|l|l|l|l|l|l|l|}
$\mathrm{C}$ & $\mathrm{Si}$ & $\mathrm{Mn}$ & $\mathrm{P}$ & $\mathrm{S}$ & $\mathrm{Cr}$ & $\mathrm{Mo}$ & $\mathrm{Ni}$ & $\mathrm{N}$ & $\mathrm{Al}$ & $\mathrm{Cu}$ \\
\hline 0.19 & 0.18 & 1.25 & 0.010 & 0.028 & 1.07 & 0.008 & 0.03 & 0.012 & 0.02 & 0.02
\end{tabular}

The determination of the phase transformation temperatures was carried out by means of a quenching and forming dilatometer BÄHR DIL 805 A/D (Figure 1). In this process, samples with dimensions of $\varnothing 4 \times 7 \mathrm{~mm}$ were heated with the rate of $2 \mathrm{~K} / \mathrm{min}$ up to $1000{ }^{\circ} \mathrm{C}$, held there for one minute and then cooled down to room temperature with the same rate. The determined phase transformation temperatures of the steel are shown in Table 2.

Table 2: Phase transformation temperatures of the investigated steel in ${ }^{\circ} \mathrm{C}$

\begin{tabular}{l|l|l|l|l|l|}
$\mathrm{Ac}_{1 \mathrm{~b}}$ & $\mathrm{Ac}_{1 \mathrm{f}}$ & $\mathrm{Ac}_{3}$ & $\mathrm{Ar}_{3 \mathrm{~b}}$ & $\mathrm{Ar}_{1 \mathrm{~b}}$ & $\mathrm{Ar}_{1 \mathrm{f}}$ \\
\hline 729 & 765 & 840 & 775 & 691 & 666
\end{tabular}

The adjustment of different types of banded microstructure was carried out on cylindrical samples with dimensions of $\varnothing 5 \times 10 \mathrm{~mm}$ using BÄHR DIL $805 \mathrm{~A} / \mathrm{D}$. The samples were machined directly from the hot-rolled wire rod. The forming and cooling parameters used in the dilatometry experiments are shown in Figure 2. Cooling rates above $2 \mathrm{~K} / \mathrm{s}$ are known to lead to bainite formation and, therefore, were not applied.
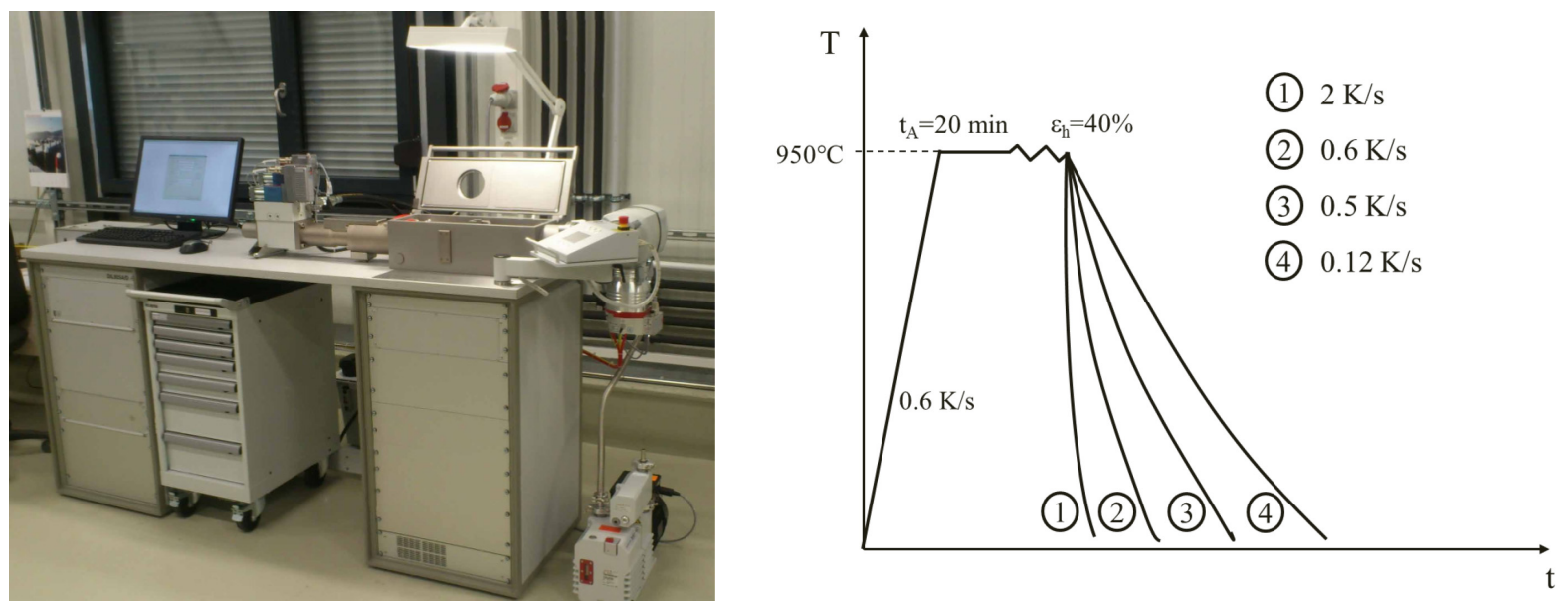

Figure 1: Quenching and forming Figure 2: Designed testing deformation-temperature dilatometer BÄHR DIL 805 A/D profile for adjustment of various pearlite banding in the dilatometer

The specimens prepared in the dilatometer with four different types of the banded microstructure as well as the wire rod in the initial state were annealed to achieve spheroidized cementite. The spheroidization annealing was performed in an air circulating furnace at a constant specimen temperature of $735^{\circ} \mathrm{C}$ for 8 and 20 hours. The heating rate up to the isothermal annealing temperature was $0.3 \mathrm{~K} / \mathrm{s}$, while the cooling from this temperature down to approximately $400^{\circ} \mathrm{C}$ was $0.5 \mathrm{~K} / \mathrm{s}$. The temperature development in the specimens during the heat treatment was measured using thermocouples. This procedure ensured that the specimen temperature never exceeded $735^{\circ} \mathrm{C}$.

Subsequently, a selection of specimens was subjected to light microscopy investigation. The ground and polished surfaces were etched using 5\% Nital solution. The micrographs were taken in the core area of the wire rod at a magnification of 200x. 
The quantification of the microstructure is based on digital image processing and requires the recognition of the ferrite and pearlite grains (see Figure 3) before evaluating the degree of pearlite banding. To quantify the degree of pearlite band formation the mean gray value of each horizontal and vertical line across the image was calculated. Along the pearlite bands (in Figure 4 horizontally) all those mean gray values exhibit a higher standard deviation than perpendicular (here vertical lines) to the banding. Thus, the ratio of this horizontal standard deviation by the vertical standard deviation is a measure for the degree of pearlite band formation (see Figure 4, right). The values for the so defined degree of pearlite banding range from 1 (no pearlite bands) to infinity.
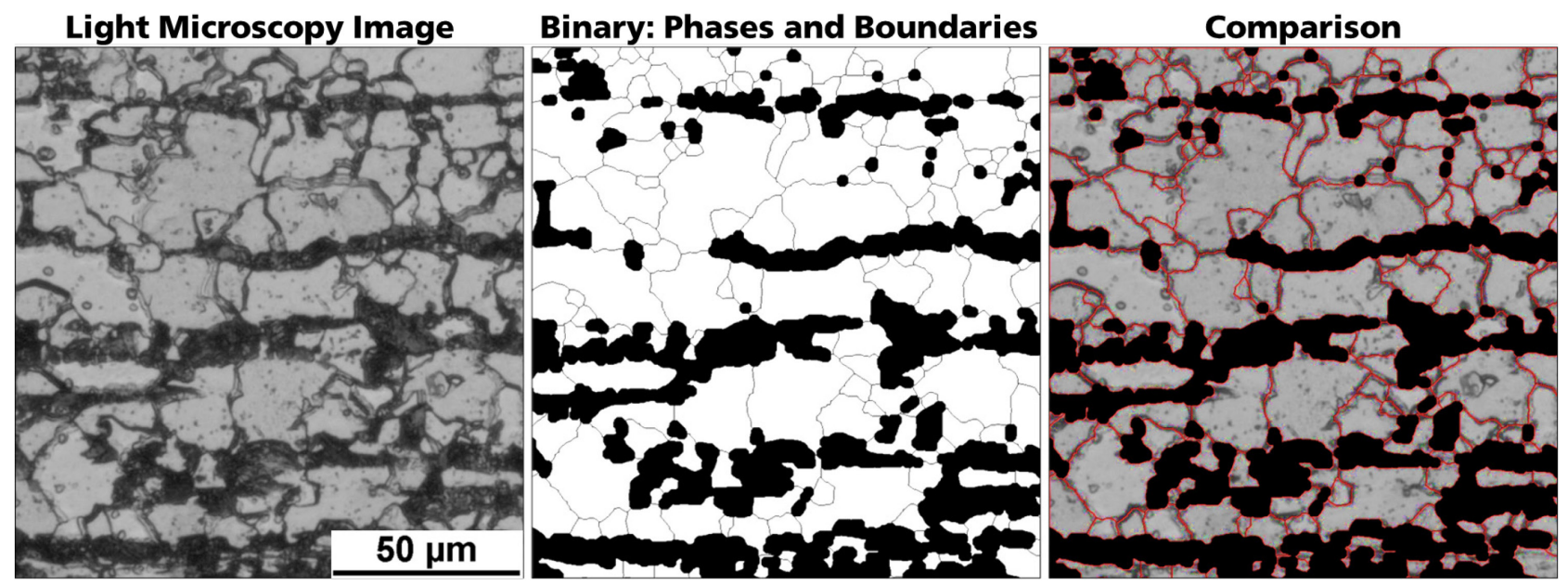

Figure 3: Digital recognition of ferrite and pearlite grains

Left: Original Light Microscopy Image

Center: Recognized Phases and Boundaries

Right: Overlay of Light Microscopy Image (left) and Phases and Boundaries (center)
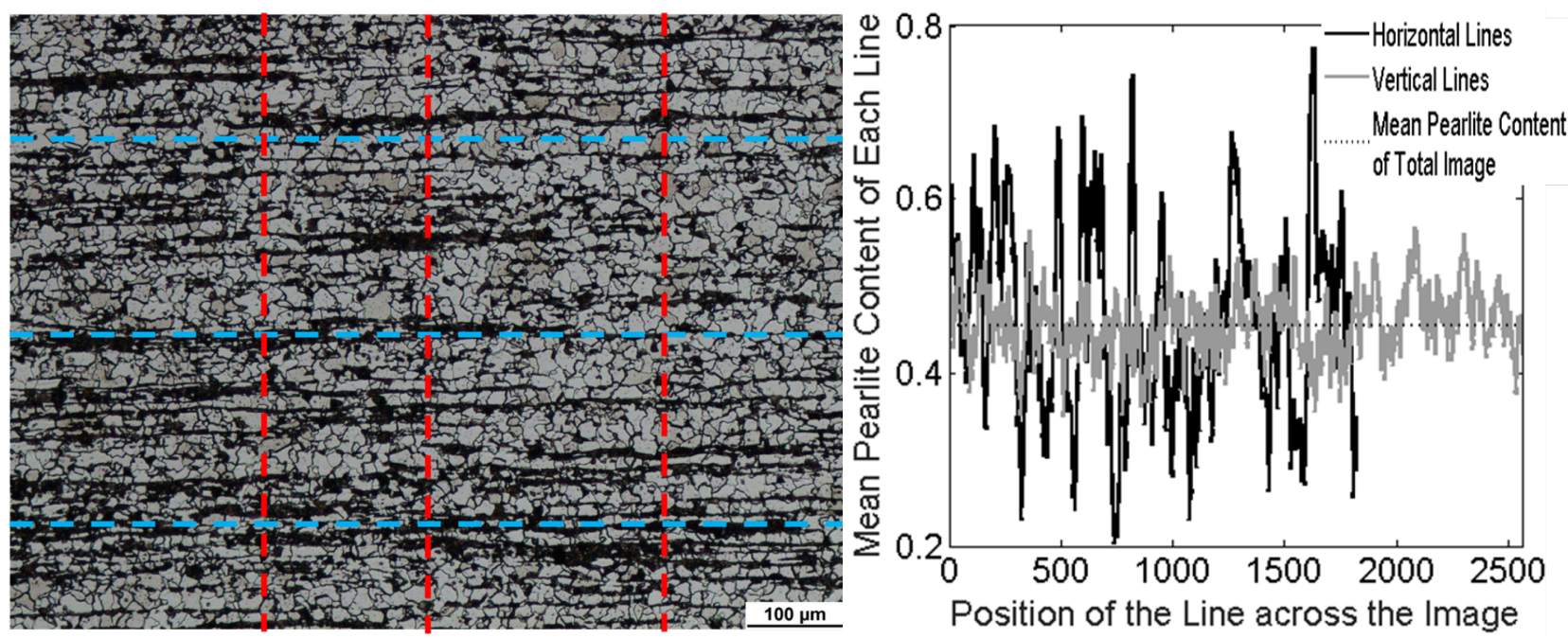

Figure 4: Quantification of pearlite banding

\section{Results}

Figure 5 shows microstructural images of the dilatometry specimens processed with the different cooling rates (see Figure 2). Here, the pearlite is the dark phase and ferrite the light phase. It occurs that the pearlite formation changes from banding to random with increasing cooling rate from 0.12 up to $2 \mathrm{~K} / \mathrm{s}$. The degrees of pearlite banding for each investigated condition are shown in the Figure 5. By varying the cooling rate the degrees of pearlite banding could be adjusted in a range between 1.0 and 3.4 . 


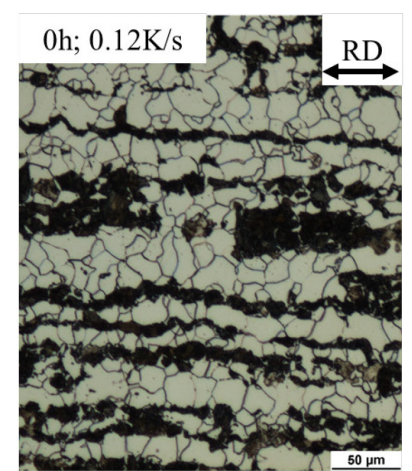

Banding degree $=\mathbf{3 . 4}$

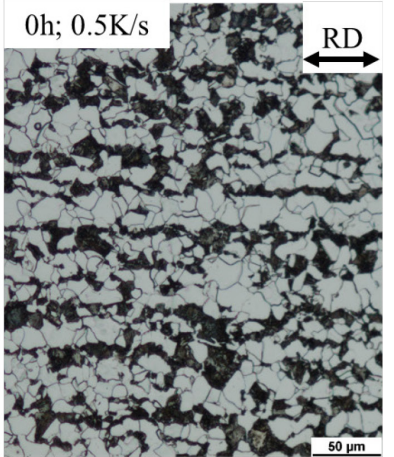

Banding degree $=\mathbf{2 . 3}$

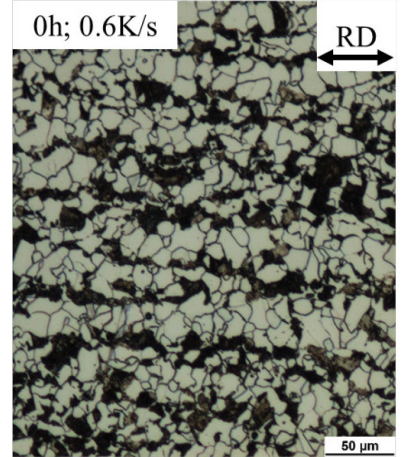

Banding degree $=\mathbf{1 . 8}$

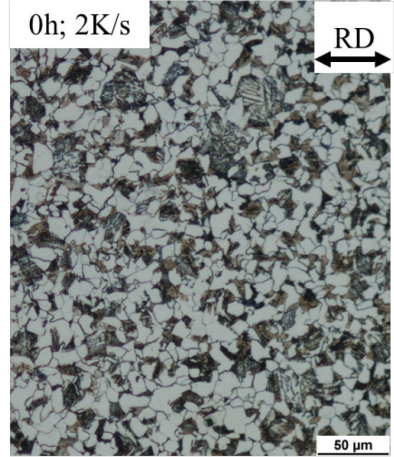

Banding degree $=\mathbf{1 . 1}$

Figure 5: Microstructure of the steel before annealing according to different cooling rates

The evolution of pearlite banding with the increasing duration of annealing is shown in Figure 6. The change in the microstructure of a dilatometry specimen with the cooling rate of $0.12 \mathrm{~K} / \mathrm{s}$ after 8 and 20 hours of annealing is shown here as example. In addition, the microstructure of an 8-hour annealed wire rod specimen is represented. It is apparent, that pearlite banding decreases with the increasing duration of annealing.

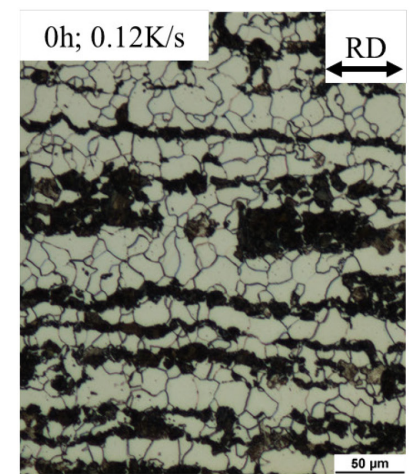

Banding degree $=\mathbf{3 . 4}$

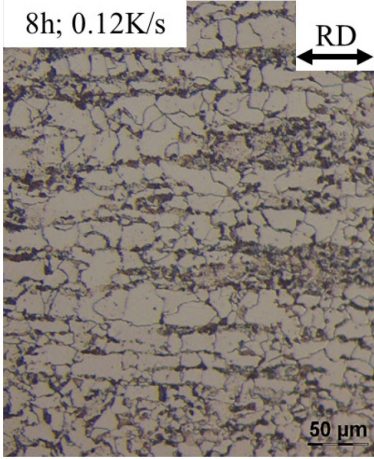

Banding degree $=\mathbf{2 . 3}$

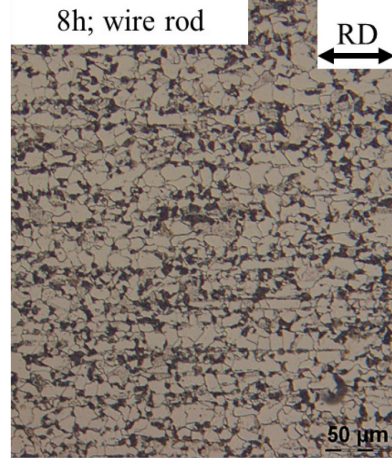

Banding degree $=\mathbf{1 . 8}$

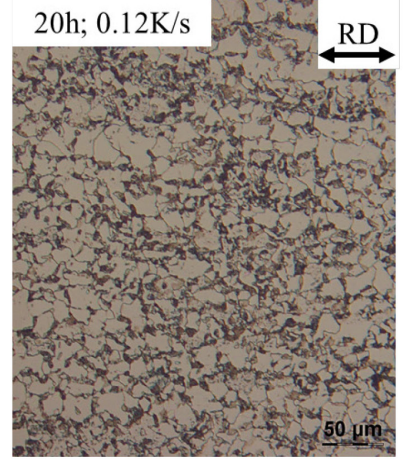

Banding degree $=\mathbf{1 . 6}$

Figure 6: Microstructure development during spheroidization annealing with the increasing duration of annealing

Figure 7 shows the effect of the cooling rate on both the formation of pearlite banding and its change with two different durations of annealing. Evidently, the relationship between pearlite banding and cooling rate is hyperbolic in the investigated range of annealing duration. The correlation coefficient between the experimental results and the approximated hyperbolic function shows very high values and is 0.98 on average. Furthermore, the evaluation of the pearlite content in the hot-rolled wire rod in the initial state reveals a similar trend and thus allows the indirect conclusion about the cooling speed in the Stelmor roller which should be ca. $0.2 \mathrm{~K} / \mathrm{s}$ according to Figure 7. It can be seen that the decreasing of pearlite banding degree increase the time of cooling. However, because this increasing is not significantly this fact does not influence the production process. 


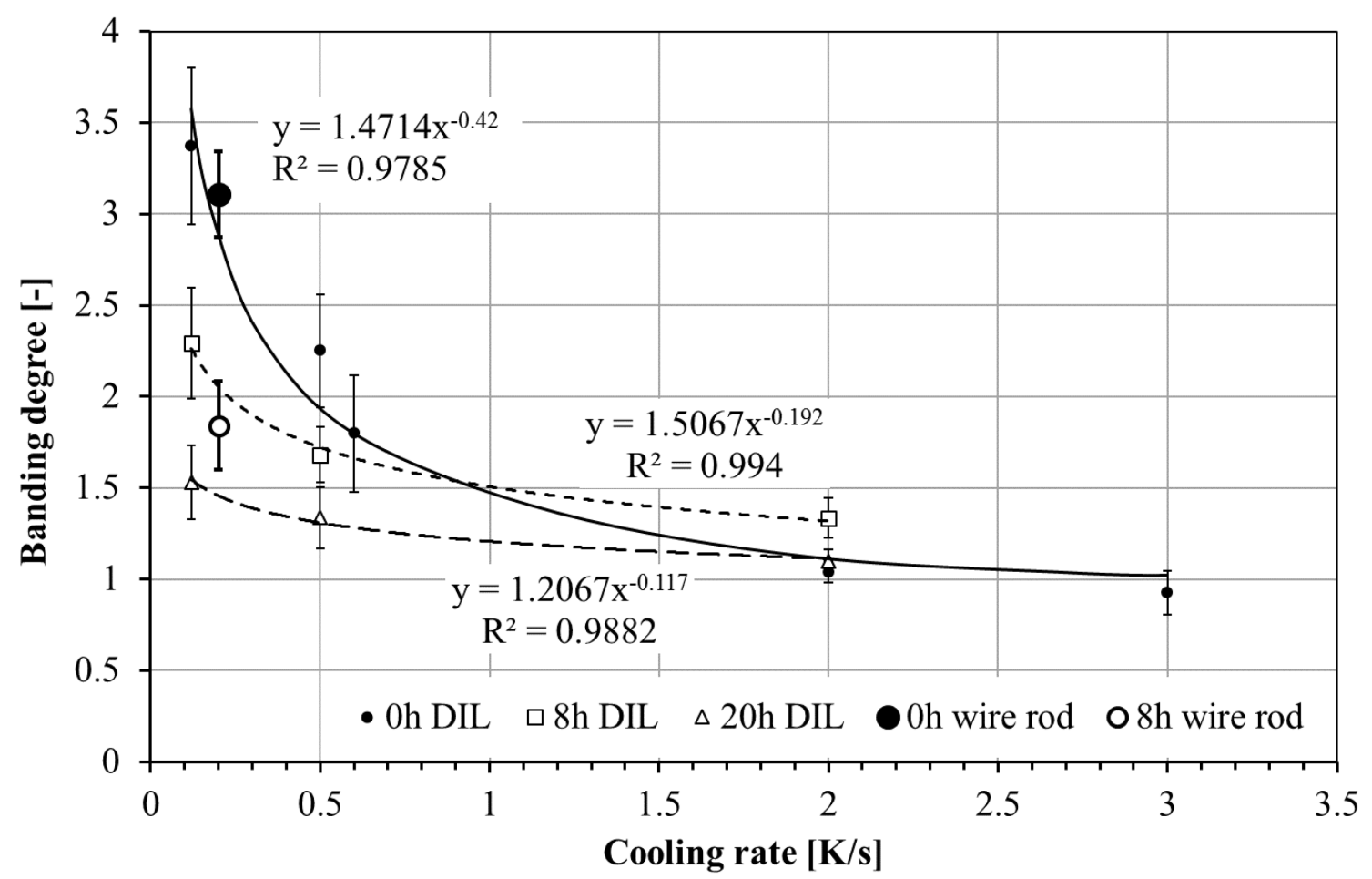

Figure 7: Relationship between the cooling rate and degree of pearlite banding for specimens before and after spheroidization annealing

\section{Discussion}

Degrees of pearlite banding determined on the basis of three annealing durations $(0,8$ and $20 \mathrm{~h})$ and their hyperbolic relationship with the cooling rate enable interpolation and extrapolation within a wider range of the annealing times. For this purpose, it is convenient to formulate a linear correlation between the annealing time and the exponent of the correlation equations from Figure 7. The coefficient of determination for this linear correlation is approximately 0.85 and can be assumed to be sufficiently accurate for practical calculations (Figure 8). Based on this assumption, the dependency of pearlite banding on the cooling rate for the annealing time between $2 \mathrm{~h}$ and $25 \mathrm{~h}$ was recalculated. Figure 8 shows that no further change of pearlite banding is expected after 25 hours of annealing. 


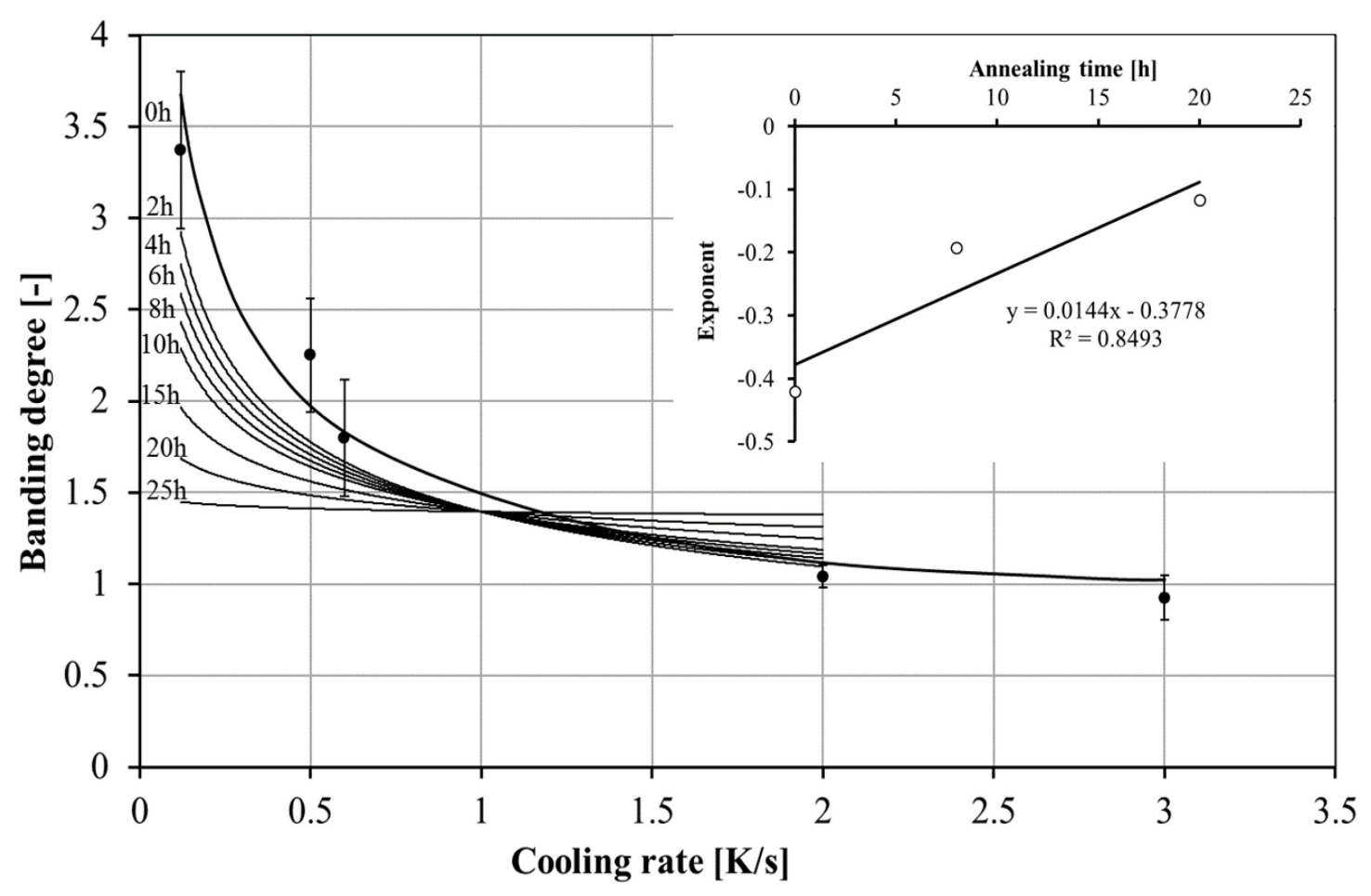

Figure 8: Relationship between the cooling rate and pearlite banding degree with the increasing annealing time

Concluding on the numerical results shown in Figure 8 and the dependency of pearlite banding on the annealing time (Figure 9), it occurs that an increasing duration of annealing leads to exponential change of pearlite banding. While higher degrees of pearlite banding (in the initial states with the cooling rates $0.12 \mathrm{~K} / \mathrm{s}$ and $0.5 \mathrm{~K} / \mathrm{s}$ ) decrease, the low degrees of pearlite banding (in the initial state with the cooling rate of $2 \mathrm{~K} / \mathrm{s}$ ) increase. The reason for such behavior can be explained by the inhomogeneous formation of cementite within and out of the primary manganese segregation regions.

In fact, it is well known, that the primary segregation of alloying elements affects the temperatures of $\gamma$ - $\alpha$-transformation $\mathrm{Ar}_{3}, \mathrm{Ar}_{1}$ and $\mathrm{Ac}_{3}, \mathrm{Ac}_{1}$. For example, manganese leads to a lowering of the $\mathrm{Ar}_{3}$ and $\mathrm{Ar}_{1}$ temperatures, namely by about $80 \mathrm{~K}$ per percent enrichment at cooling rates of 1 to $3 \mathrm{~K} / \mathrm{s}$, where banded pearlite is formed [7, 8]. Local microstructure regions with higher content of alloying elements have lower $\mathrm{Ar}_{3}$-temperature. This accelerates cementite spheroidization in the regions with higher concentration of alloying elements. 


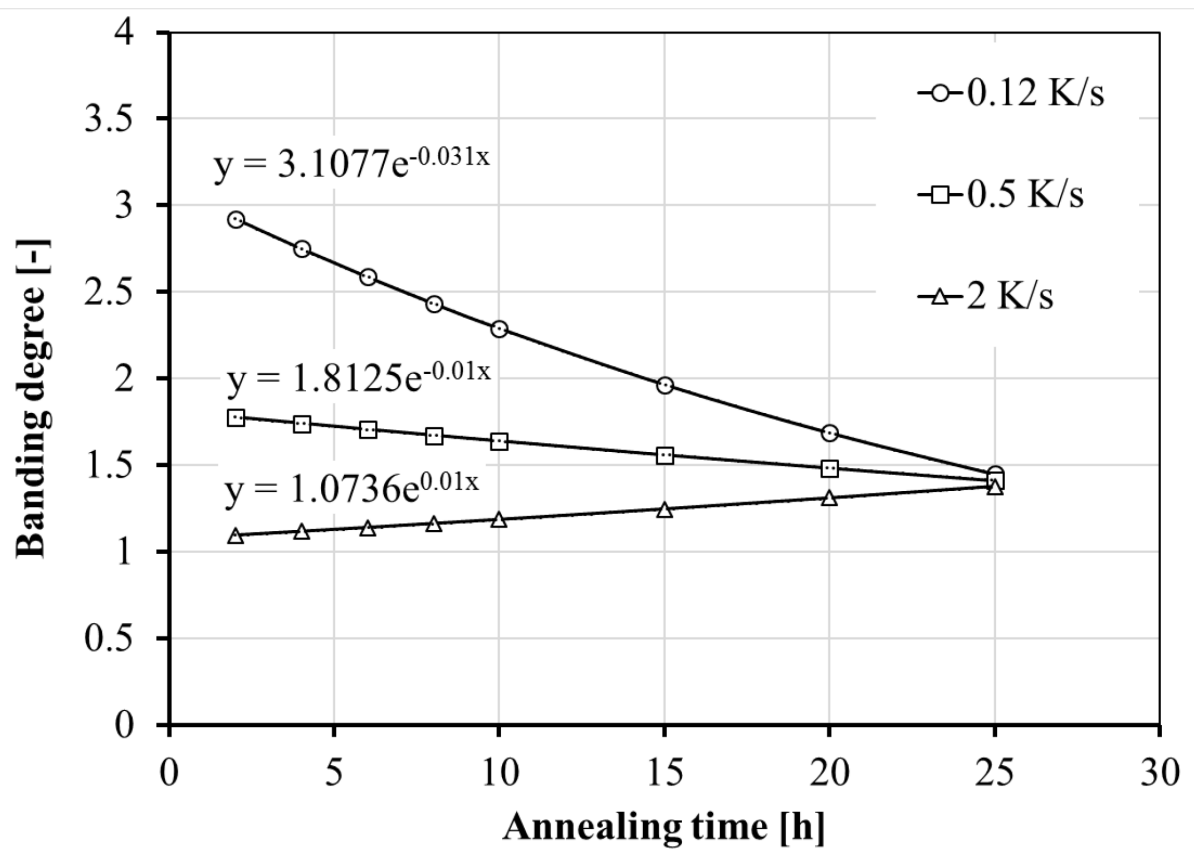

Figure 9: Relationship between the annealing time and pearlite banding degree

The obtained results as well as the conclusions will be deepened in further investigations and validated on other steel grades.

\section{Summary}

The following conclusions can be drawn from this study:

1. Pearlite banding could be adjusted for the investigated steel $16 \mathrm{MnCrS} 5$ in a range between 1.1 and 3.5.

2. The approach applied for the evaluation of pearlite banding showed representative and reproducible results.

3. The relationship between the degree of pearlite banding and the cooling rate is of the hyperbolic type.

4. The increasing duration of isothermal spheroidization annealing led to the exponential decrease of initially pronounced pearlite banding, while initially weak pearlite banding increased.

5. The results obtained for the dilatometry specimens and industry related material showed a very good agreement.

\section{Acknowledgements}

The authors gratefully acknowledge the financial support of the German Cold Forging Group (GCFG) for this investigation.

\section{References}

[1] S. E. Offerman, N. H. van Dijk, M. Th. Rekveldt, J. Sietsma \& S. van der Zwaag: Ferrite/pearlite band formation in hot rolled medium carbon steel. Materials Science and Technology 18 (2002) 3, pp. 297/303

[2] F. D'Errico: Failures Induced by Abnormal Banding in Steels, J. Fail. Anal. and Preven, 10 (2010) pp. 351/357

[3] F.A. Khalid, M. Farooque, A. ul Haq, A.Q. Khan: Role of ferrite/pearlite banded structure and segregation on mechanical properties of microalloyed hot rolled steel. Materials Science and Technology 15 (1999) 10, pp. 1209/1215 
[4] M. Hunkel: Analyse von Seigerungen und seigerungsbedingtem Verzug am Beispiel des Einsatzstahls 20MnCr5, HTM 67 (2012) 5, pp. 311/21

[5] Wang Bin, Hu Hong-Mei, Zhou Cui: The Method of Eliminating Banded Structure and the Effects of Banded structure on the Transverse Properties in 20G Steel, Applied Mechanics and Materials, 347-350 (2013) pp. 1171/1175

[6] S. W. Thompson, P. R. Howell: Factors influencing ferrite/pearlite banding and origin of large pearlite nodules in a hypoeutectoid plate steel. Materials Science and Technology 8 (1992) pp. Pages 777/784

[7] R. Kawalla; C. Lang; U. Lotter: Beitrag der quantitativen Metallographie zur Optimierung von Gefügen, Stahl und Eisen 114 (1994) 7, pp. 61/69

[8] R. Großterlinden; R. Kawalla; U. Lotter; H. Pircher: Formation of pearlitic banded structures in ferritic-pearlitic steels, Steel Research 63 (1992) 8, pp. 331/336 